\title{
Investment, Hysteresis, and Layers of Techniques: A Case Study of Agricultural Manufacturing Machinery in Multan Division
}

\author{
TOSEEF AzID and MuHAMMAD AKBAR NOOR
}

\section{INTRODUCTION}

The behaviour of firms is still a little understood matter. Why one firm or industry is investing more than the other or what makes a firm enter or exit from the market, what are the psychological factors that go to make a choice of this kind are questions that have not been answered satisfactorily.

Concepts like irreversibility, uncertainty, investment, and the value of waiting are very much there in the literature, e.g., McDonald and Siegel (1985, 1986); Nickell (1974); Schmalensee (1972); Hartman (1972); Henry (1974) and LAM (1989) and others. But the psychology of decision-making on the face of losses has not received much attention in the literature. That the Economic Hysteresis ${ }^{1}$ and Layers of Techniques ${ }^{2}$, developed by Professor A. Dixit and Professor P. N. Mathur respectively tackle. The former is discussed by Pindyck (1988, 1991, 1992) and Dixit (1989, 1989a, 1991, 1992); while Mathur (1977, 1989, 1990); Law and Azid (1993); Azid and Ghosh (1998) and Rashid (1989,1989a) have discussed the latter.

Toseef Azid is Associate Professor, Economics Department, Bahauddin Zakariya University, Multan. Muhammad Akbar Noor is Lecturer in Economics at Government College, Civil Lines, Multan.

Authors' Note: We would like to thank Professor Abid Aman Burki of Quaid-i-Azam University for his valuable comments on this paper.

${ }^{1}$ This concept is borrowed from Physics. Take an iron bar and loop an insulated wire around it. Pass an electric current through the wire; the iron will be magnetised. Now switch the current off. Some magnetism stays. The cause (the current) was temporary, but left some lasting effect (the magnetised bar). This phenomenon is called hysteresis, and by analogy the failure of investment decisions to reverse themselves when the underlying causes are fully reversed can be called economic hysteresis.

${ }^{2}$ This concept is borrowed from geology. The geological layers we see sometimes on river banks may have different characteristics. This is what the structure of the industry is. 
Dixit (1989) emphasised the concept of hysteresis. He discussed entry and exit decisions under uncertainty (1989), irreversibility with price ceilings (1991) and investment and hysteresis (1992). He advocates examination of a firm's entry and exit decisions when the output price follows a random walk situation. An idle firm and an active firm are viewed as assets that are called options to each other. He suggested a pair of trigger prices for entry and exit. The entry trigger exceeds the variable cost plus the interest on the entry cost, and the exit trigger is less than the variable cost minus the interest on the exit cost. These gaps produce "hysteresis" which is significant even with small sunk costs.

On the other side the phenomenon of layers of techniques developed by Professor Mathur $(1977,1989,1990)$ emphasises that the exit problem is not only based on future expectations but is also related to the technology applied in the production process. According to him the objective of the producer is not only to protect himself from losses in the long run but also to minimise his share in the sunk cost of capital. Law and Azid (1993) and Azid and Ghosh (1998) discussed both concepts in their study and found that the first thing to determine the price regime of the products, whether it was fix or flex. They concluded that the decision of the manufacturer about abandonment was also based on the layers of techniques. However, there was no serious attempt to apply both concepts to entry as well as exit decisions of the firms.

The current literature on economic studies concentrates on project appraisal. It uses the general Marshallian techniques for both kinds of decisions. In reality this is not the situation. The behaviour of firms is not so mechanised as traditionally held. This study analyses the behaviour of manufacturers of agricultural machinery in Multan in the context of investment, hysteresis and layers of techniques based on a survey conducted in Multan Division on account of its machinery concentration.

Secondary data on why the manufacturers are not abandoning the market even in loss situations was not available. A survey of all registered firms was therefore conducted through a questionnaire for direct interviews of the manufacturers. The questionnaire was pretested. There were 50 manufacturers in all.

Their demographic profile is given in Table 1 . which shows that only 6 percent are illiterate. Most of them have had schooling from primary to matric levels. Although the number of the highly educated manufacturers was not large yet at 20 percent it was reasonable. Table 1 also depicts the age profile of the manufacturers: all are above 22 years with the majority in the age group of 36 to 45 years. Another aspect to be analysed the age of the business. Table 1 depicts a uniform distribution in this respect. 
Table 1

Demographic Profile of the Manufacturers

\begin{tabular}{lc}
\hline \multicolumn{2}{c}{ Percentage of Manufacturers } \\
\hline Education of Manufacturers & $6 \%$ \\
Illiterate & $16 \%$ \\
$1-5$ & $32 \%$ \\
$6-10$ & $26 \%$ \\
$11-13$ & $20 \%$ \\
Higher Education & \\
Age of Manufacturers & $0 \%$ \\
Less than 21 Years & $16 \%$ \\
22-35 Years & $58 \%$ \\
36-45 Years & $26 \%$ \\
More than 45 Years & \\
Age of Business & $21 \%$ \\
1-5 Years & $32 \%$ \\
6-10 Years & $26 \%$ \\
$11-15$ Years & $21 \%$ \\
16-20 Years & \\
\hline
\end{tabular}

\section{EMPIRICAL FINDINGS}

The empirical analysis is divided into three sub-sections. The analysis in subsection 2.1 is based on manufacturers who incurred losses, i.e., their AVC was greater than the price. Almost 40 percent of them have observed losses in the past, which is a significant number. Sub-section 2.2 is based on the 2nd phase of the survey. All the manufacturers were approached to test the results of sub-section 2.1 for which a logit model was used in sub-section 2.3. However, it is assumed in the study that four types of technologies are employed in this sector-best, average (more efficient) average (less efficient) and the worst. The average efficient age of a technology is about five years after which a new efficient technology enters the market, that is completely different from the older one.

\subsection{Managerial Efficiency}

It is assumed in the literature that the decision of a manufacturer is also determined by his managerial skill [Awa and Batra (1998)] which is a qualitative variable. In this study therefore some proxy variables have been employed. The ages of business and of the manufacturers and their education are considered to be pseudo variables for managerial skill. Table 2 depicts the age of the business and the age and education of the manufacturers at the time of the loss. 
Table 2 shows that the higher percentage of those manufacturers who did not quit the market belonged to the group with $6-10$ years experience (48 percent), whereas the lower percentage is 14 percent in both 'less than 5' and '11-15' categories . The newly entered manufacturer have no strong forecasting ability so they left the market or, may be, in this class the number of firms that observed the losses was not very high because the new techniques were more efficient than the older one. The percentage of those firms is maximum which used the average technology of the more efficient type. The factors that led to non-abandonment in face of losses are an average business age, average technology, greater sunk cost as working capital and a trained labour force (Law and Azid 1993).

Table 2

Age of Business, Age and Education of the Manufacturers at the Time of Loss

\begin{tabular}{lcc}
\hline & \multicolumn{2}{c}{ Percentage of Manufacturers } \\
\hline Age of Business & \\
(Best) & Less than 5 & $14 \%$ \\
(Average:More Efficient) & $6-10$ & $48 \%$ \\
(Average:Less Efficient) & $11-15$ & $14 \%$ \\
(Worst) & More than 15 & $24 \%$ \\
Age of manufacturers & \\
Less than 21 & $\mathbf{0 \%}$ \\
22-35 & $24 \%$ \\
36-45 & $62 \%$ \\
More than 45 & $14 \%$ \\
Education of Manufacturers & \\
Illiterate & $0 \%$ \\
1-5 & \\
6-10 & $0 \%$ \\
11-13 & $62 \%$ \\
Higher Education & $24 \%$ \\
\hline
\end{tabular}

It means that the degree of sunk cost is also more important for their decisionmaking, the higher the sunk cost, the lower the chances to leave the market. Another variable, which has significant effect on this behaviour, is retrofitting, as it can reduce their variable cost per unit of output rather than the older firms [Azid and Ghosh (1998)].

As discussed by Prof. Mathur, retrofitting (a slight change) in the process, can increase the efficiency of the plant and in this way both the financial cost and time can be saved instead of replacing the whole plant. Plants of more than 10 but less than 15 years of age cannot compete without retrofitting. But naturally the degree of efficiency which they will gain will be less and the cost higher than those using average technique (more efficient). This may be the time for them to decide whether 
to leave or to survive in the market through retrofitting.. It seems more realistic for older technologies to go through the process of retrofitting. Also the manufacturers of these firms have spent a lot of time in this business employing the sunk cost of the firms. Whereas the average technologies (more efficient) have more sunk cost than all the others in terms of manufacturers' experience, working capital and investment on retrofitting.

It is concluded from the above discussion that the age of the business may also have an effect on the perception of the manufacturers towards sunk cost of capital and the brightness of future. The psychological state of the manufacturer may be dependent on that layer of technology, which he uses, e.g., those who use new technology expect that the future is not so bright since if they cannot cover average variable cost with this efficient technology now how they will fare in future. Both groups, (6-10 and above 15) think that if they leave the market their degree of sunk cost will be higher. Another aspect is the inter-group comparison, i.e., the second group (user of average but more efficient technology) is comparing itself with the first group (user of efficient technology). Whereas the fourth (user of worst technology) is comparing itself with the third group (user of average but less efficient technology). They may be thinking in terms of profit, which they will reap in the future, if the first and third group leave the market. Another variable, which is assumed to represent the managerial skill, is the age of the manufacturer.

Table 2 also shows that the middle age group like to take risks more than the younger and the older ones. Aged manufacturers have no gall for risks. This shows that the age of the manufacturer plays an important and crucial role in making their decisions. The young manufacturers can divert themselves to another business not because they cannot take risk but because they are in position to change the dimension of the risk, something the older than 45 cannot do being not strong enough to take new risk. Beside future expectations, the phenomenon of layers of techniques also works simultaneously, i.e., the middle age group has experience as well as spirit, so this group in comparison to other groups may easily adopt the policy of retrofit for his survival.

Table 2 also depicts the educational level of manufacturers at the time of loss. It is observed that the highly educated manufacturers are not satisfied with the future of the industry whereas the under-matriculates are very much sure about the future. It seems from Table 2 that the degree of risk-aversion is increasing with the level of education of manufacturers.

It is also observed that not a single manufacturer is illiterate, either they left the market thinking the future was not bright or they did not enter at all. On the other hand the highly educated who can easily perceive the future thought the future to be not so bright. The number of highly educated people in the business was very low at the time of loss. 
It is observed from the above analysis that the age of the firm -6 to 10 , education of the manufacturer from 6 to 10 and age of the manufacturer -36 to 45 , is having more percentage of manufacturers who did not leave the market even after observing the losses.

As stated by Mathur (1989) that in any economy a number of technologies are working simultaneously with different efficiencies. In the industrial sector where fixed prices are prevailing, technology is an important and crucial variable in the decision about abandonment.

\subsubsection{Causes of Loss}

When the reasons of the loss were explored it was found that manufacturers in the age group 1-5, through that local competition was the main reason. This is an interesting finding already explained in the vintage capital model of Mathur (1989), i.e., new techniques always have cost advantage; if they incurred loss, it was mainly due to less demand rather than obsolescence or other variables. Less demand whether in absolute or relative term, means the market share of those firms is reduced from the past level. Firms, which are at the age of 6-10, have different explanation for the loss. Among them 20 percent was faced with the problem of working capital at the time of the losses. In this state of the emergency they might have borrowed the needed capital at a rate higher than the prevailing market rate (this will increase the AVC). Among them 40 percent thought the reason was low demand, whereas 20 percent blamed political instability and 20 percent simply thought the $\mathrm{P}<\mathrm{AVC}$. The above phenomenon is easy to understand in term of layers of techniques. Those manufacturers who were using average but less efficient techniques favoured the $\mathrm{P}<\mathrm{AVC}$ position. But the users of the oldest techniques blamed less demand for the losses.

The analysis based on the age of the owner shows manufacturers falling in the 22-35 age group blaming lower demand and the entrance of new firms as the main cause of the loss. The age group of 36-45 is divided equally along three reasons, Less Demand, $\mathrm{P}<\mathrm{AVC}$, and political instability. Half of the owners above 45 years blame financial crisis and the rest half low demand.

Manufacturers with different levels of education considered less demand as the basic reason for the loss, incurred in the past. Table 3 shows where financial problem and competition have also been pointed out as the reason. Among them the highly educated show sensitivity towards the price of financial capital.

Dixit (1992) and Pindyck (1991) are of the view that abandonment is also based on the loss of trained labour force. This response, in monetary terms, is shown in Table 4. 
Table 3

Demographic Characteristics of Manufacturers and Causes of Loss

\begin{tabular}{|c|c|c|c|c|c|}
\hline & $\begin{array}{c}\text { Financial } \\
\text { Problem }\end{array}$ & $\begin{array}{c}\text { Less } \\
\text { Demand }\end{array}$ & $\begin{array}{c}\text { Local } \\
\text { Competition }\end{array}$ & $\begin{array}{c}\text { Political } \\
\text { Instability }\end{array}$ & $\mathrm{P}<\mathrm{AVC}$ \\
\hline \multicolumn{6}{|l|}{ Age of Business } \\
\hline $1-5$ & - & - & $100 \%$ & - & - \\
\hline $6-10$ & $20 \%$ & $40 \%$ & - & $20 \%$ & $20 \%$ \\
\hline $11-15$ & - & - & - & - & $100 \%$ \\
\hline $16-20$ & - & $100 \%$ & - & - & - \\
\hline \multicolumn{6}{|l|}{ Age of Manufacturer } \\
\hline Less than 21 & - & - & - & - & - \\
\hline $22-35$ & - & $50 \%$ & $50 \%$ & - & - \\
\hline $36-45$ & - & $34 \%$ & - & $34 \%$ & $32 \%$ \\
\hline More than 45 & $50 \%$ & $50 \%$ & - & - & - \\
\hline \multicolumn{6}{|c|}{ Education of Manufacturer } \\
\hline Illiterate & - & - & - & - & - \\
\hline $1-5$ & - & - & - & - & - \\
\hline $6-10$ & - & $34 \%$ & $32 \%$ & - & $34 \%$ \\
\hline $11-13$ & - & $100 \%$ & - & - & - \\
\hline Higher Education & $50 \%$ & $50 \%$ & - & - & - \\
\hline
\end{tabular}

Table 4

Loss of Trained Labor Force in Monetary Terms

\begin{tabular}{lccc}
\hline & Below 1 Lakh & $1-2$ Lakh & $2-3$ Lakh \\
\hline Age of Business & $100 \%$ & - & - \\
$1-5$ & $20 \%$ & $20 \%$ & $60 \%$ \\
$6-10$ & $30 \%$ & $30 \%$ & $40 \%$ \\
$11-15$ & $100 \%$ & - & - \\
$16-20$ & & & - \\
Age of Manufacturers & - & - & $34 \%$ \\
Less than 21 & - & $66 \%$ & $32 \%$ \\
22-35 & $34 \%$ & $34 \%$ & $52 \%$ \\
36-45 & $32 \%$ & $16 \%$ & - \\
More than 45 & & & - \\
Education of Manufacturers & $100 \%$ & - & $16 \%$ \\
Illiterate & - & $33 \%$ & - \\
1-5 & $16 \%$ & $68 \%$ & $32 \%$ \\
$6-10$ & $80 \%$ & $20 \%$ & $34 \%$ \\
$11-13$ & $34 \%$ & & \\
Higher Education & & 3 & \\
\hline
\end{tabular}

Users of obsolescent techniques, estimated the loss of labour to around one lakh. The users of new technologies have given the same response. This would imply that the users of new technologies have not spent so much time as well as cost on the training of labour force. Why have the users of old techniques under estimated the loss? The answer is very simple. They think that their trained labour force is not now useful for the new techniques and also since they have earned enough income from 
this technology they can take their loss of trained workers in monetary terms to be less than for users of average techniques. Users of average techniques (more and less efficient) estimated their loss to around 3 lakhs.

\subsection{Expectations and Targets of the Manufacturers}

Abandonment as mainly explained by Dixit (1992) and Pindyck (1988) is an economic phenomenon based on good or bed expectations of manufacturers about future. The analysis of this Section is based on the 2nd phase of the survey. All the manufacturers were approached, and their opinions were collected. They were asked if they incurred loss in future (AVC > P), what will be their expected reaction? No one responded that he would leave the market. They expected the future to be bright or that they would try to reduce the AVC through improvement in the production process. In Table 5, a weighted average was estimated about these two options of each category.

Table 5

Expected Response of Manufacturers if AVC $<P$ (A Weighted Average)

\begin{tabular}{lcc}
\hline & Bright Future & $\begin{array}{c}\text { Improvement in the } \\
\text { Production Process }\end{array}$ \\
\hline Age of Business & $72 \%$ & $28 \%$ \\
$1-5$ & $40 \%$ & $60 \%$ \\
$6-10$ & $20 \%$ & $80 \%$ \\
$11-15$ & $50 \%$ & $50 \%$ \\
$16-20$ & & \\
Age of Manufacturers & $30 \%$ & $70 \%$ \\
$22-35$ & $60 \%$ & $40 \%$ \\
$36-45$ & $44 \%$ & $56 \%$ \\
Above 45 & & \\
Education of Manufacturers & $50 \%$ & $50 \%$ \\
$6-10$ & $32 \%$ & $68 \%$ \\
$11-13$ & $42 \%$ & $58 \%$ \\
Higher Education & & \\
\hline
\end{tabular}

No unexpected result is seen in Table 5. For example, the users of new technology expect a bright future whereas users of average technology (less efficient) give more weight to improvement in the production process.

As explained by Dixit (1992) that economic theory of investment under competitive conditions rested on Marshall's analysis of long and short-run 
equilibrium. If prices exceed long-run average cost, it induces existing firms to expand and new ones to enter. If prices fall below the average variable cost, then the firm suspends operations or even exits from the market. According to Dixit (1992) and Pindyck (1991) the reality was very different. Firms invest in projects that they expect to yield a return in excess of a required "hurdle" rate. Observers of business practice find that such hurdle rates are three or four times the cost of capital, e.g.; Summers (1987) found hurdle rates ranging from 8 to 30 percent, with a median of 15 and mean of 17 percent. In other words, firms do not invest until prices rise substantially above long-run average cost. The hurdle rate appropriate for investment with systematic risk will exceed the risk-less rate, but it seems hard to justify the large discrepancies observed. On the downside, firms stay in business for a long period while observing operating losses, and prices can fall substantially below average variable cost without inducing disinvestment or exit. Keeping this in view opinion of manufacturers was collected about this hurdle or target rate under uncertainty.

From Table 6 it is observed that the users of the worst technique have the downside target rate that is equal to the upside potential rate; but the users of the best and average technique have the higher upside potential rate than the downside rate. The range of the upside rate is greater than the range of the downside rate. If the uncertainty is low, there can be little value in waiting and if the uncertainty is high, setting a high trigger before taking action may avoid some very bad outcomes. Table 10 depicts that for the manufacturer entry is more risky than exit from the market. It is also clear from this Table that the value of waiting is different for different layers of techniques. One can also conclude from this behaviour that if a firm ceases operation (even temporarily) it cannot restart without incurring some further cost. It is as if the machinery rusts when unused. The downside risk reduces with the age of the business or, in other words, the degree of risk is dependent on the age of the technology under use.

Table 6

Target Rate of Return and Losses

\begin{tabular}{lcc}
\hline Age of Business & $\begin{array}{c}\text { Target Rate for Losses } \\
\text { (Below Price) } \\
\text { (Average) }\end{array}$ & $\begin{array}{c}\text { Target Rate of Return } \\
\text { (Above Normal Rate) } \\
\text { (Average) }\end{array}$ \\
\hline $1-5$ & $20 \%$ & $30 \%$ \\
$6-10$ & $15 \%$ & $25 \%$ \\
$11-15$ & $15 \%$ & $20 \%$ \\
$16-20$ & $10 \%$ & $10 \%$ \\
\hline
\end{tabular}


Three features are common to most investment decisions: an investment entails some sunk cost, the economic environment has an ongoing uncertainty, and an investment opportunity does not generally disappear if not taken immediately i.e., it is not only whether to invest but also when to invest. When these three conditions are present, waiting has a positive value. Time brings more information about the future prospects of the project. As long as the opportunity to invest remains available, a late decision can be the better one. And because there are sunk costs, it does not always pay to take a less perfect action now and change that later.

Of course, the value of waiting must be set against the sacrifice in terms of current profit. If current conditions become sufficiently favourable, one eventually takes the action that is optimal. But the "trigger" level of the currently expected profit that makes it optimal to proceed exceeds the Marshallian normal return. Similarly, waiting has value when contemplating disinvestment.

This view of investment under uncertainty can be summarised as "a theory of optimal inertia” or "a benevolent tyranny of the status quo". It says that firms that refuse to invest even when the currently available rates of return are far in excess of the cost of capital may be optimally waiting to be surer that this state of affairs is not transitory. Likewise, businessmen who carry large losses may be rationally keeping their operation alive on the chance that the future may be brighter.

The verbal argument above is purely qualitative; it says that waiting has a positive value, but not whether this value is typically large enough to have a significant impact on investment and disinvestment decisions.

In this survey when the entire manufacturers were asked about the reasons that made them to wait and not enter the business immediately, when they considered that to be a good opportunity to avail, the majority response was that the rate of return was not the major reason. Other variables were also considered by them, the more prominent variable being limited financial resources.

\subsection{Results of the Logit Model}

In this section an attempt has been made to apply the probability models to understand the behaviour of the manufacturer. One of the main conclusions in sub-section 2.1 and sub-section 2.2 was that abandonment was not only based on the price and average variable cost, but also depended on several other reasons, e.g.; demographic characteristics of manufacturers, their psychological state, perception about the future and specially on the layers of techniques. An understanding of the characteristic that had an independent effect on the exit probability, in relation to other characteristics will make the variables more explicit. This may be the first step towards finding the causes of exit for manufacturers who incurred the losses. For this purpose a non linear, vis. the logit model, was estimated. 
Probability models such as the logit model are used to predict the probability of the occurrence of an event and to identify the variables that are significant in determining this occurrence. These models carry a special importance in the analysis of qualitative phenomenon such as the psychological status of the manufacturer etc, since they can reveal what characteristics of the manufacturer are significant in determining his exit decision. The results of these models complement the findings of the exercise of one-way classification, which decomposes this variable across this exercise since they show the effect on exit, attributed to a change in a single characteristic of the manufacturer. In this study, we are interested in finding out whether a change in a specific characteristic of the manufacturer would increase or decrease the probability that the manufacturer will wait or not, given that all other characteristics stay unchanged. The estimated coefficient of the logit model can provide us this information. This model can be expressed as:

$$
\log P i / 1-P i=B_{k} X i_{k}
$$

Given $P i$ as the probability that the manufacturer with certain characteristics will not quit the market. The rationale of the two terms, $P i$ and $1-P i$, will give us the odds that the manufacturer will not quit the market. The coefficient of each variable can then be interpreted as change in the log of the odds that the manufacturer will not leave the market given change in the particular characteristic, keeping all other characteristics unchanged. A positive coefficient would show a greater probability the that manufacturer not leaving the market in comparison to other manufacturers and vice versa.

In the following paragraphs, only the results of the model for the categorical variables are discussed based on the level of education, the age of business and the age of the owner. Only the results of the variables found statistically significant at 0.05 level of significance will be discussed.

The logit model is used to study the manufacturing decision of fifty manufacturers of agricultural manufacturing machinery in Multan division. The responses to the survey provide a list of attributes of the manufacturers. The model takes the form,

$$
\log \frac{\text { prob.(no.) }}{1-\text { prob.(no) }}=\beta_{1}+\beta_{2} Z_{2}+\ldots \ldots . .+\beta_{k} Z_{k}
$$

Where Z's represent the attribute listed in Table 7 and the probability number represents the probability of a manufacturer to not quit the market even when suffering the Marshallian loss, i-e; AVC > price.

Note that since the observations are of individuals and not of groups, the logit model was estimated using a maximum-likelihood estimation procedure. 
Table 7

Definition of the Variables

\begin{tabular}{llll}
\hline \multicolumn{2}{c}{ Education of Manufacturers } & \multicolumn{1}{c}{1} & \multicolumn{1}{c}{0} \\
& $\mathrm{E}_{1}$ & $6-10$ & Otherwise \\
& $\mathrm{E}_{2}$ & $11-13$ & Otherwise \\
Age of Business & $\mathrm{E}_{3}$ & Above 13 & Otherwise \\
& & & \\
& $\mathrm{A}_{1}$ & $1-5$ & Otherwise \\
& $\mathrm{A}_{2}$ & $6-10$ & Otherwise \\
& $\mathrm{A}_{3}$ & $11-15$ & Otherwise \\
Age of Manufacturers & $\mathrm{A}_{4}$ & More than 15 & Otherwise \\
& & & \\
& $\mathrm{O}_{1}$ & $22-35$ & Otherwise \\
& $\mathrm{O}_{2}$ & $36-45$ & Otherwise \\
& $\mathrm{O}_{3}$ & More than 45 & Otherwise \\
\hline
\end{tabular}

$$
\begin{aligned}
\log \frac{p i}{1-p i}= & 6.15+1.09 E_{1}+0.43 E_{2}-0.09 E_{3} \\
& (3.02)^{*} \quad(2.09)^{*} \quad(2.93) * \quad(1.03) \\
& -0.03 A_{1}+2.39 A_{2}-0.37 A_{3}+1.22 A_{4} \\
& (0.97) \quad(3.84)^{*} \quad(1.39) \quad(3.27)^{*} \\
& +1.34 O_{1}+2.57 O_{2}-1.03 O_{3} \\
& (2.99)^{*} \quad(2.79)^{*} \quad(1.06)
\end{aligned}
$$

Where $P i=$ probability that manufacturer will chose not to quit the market.

The above estimations show that the probability of not to quit the market first increases with the age of the manufacturer and then decreases, the same effect is observed with the level of education. The age of the business has a mixed effect. But it is very interesting to note that those variables, which are significant at 5 percent, level of significance, have a positive sign. Whereas all other variables which have insignificant effect, show the negative sign. The results of the logit model are similar to one way classification, explained in sub-section 2.1.

One encouraging aspect observed from the results, is that the classification of different demographic characteristics has its own significance.

The education of the manufacturer shows a very interesting effect, i.e. up to the undergraduate level the decision not to leave the market is significantly affected 
by the above-mentioned variable whereas higher education has no effect on the decision, even the sign is negative though insignificant. The age of business is also included in the logit model. The results suggest that the decision of the manufacturer not to quit the market is also based on the segment of the age in which that firm is working. If some one considers the layers of technique, the average (more efficient) and the worst technique significantly affect the option of the manufacturer whereas the best technique and average (less efficient) do not have any significant effect on the choice of the manufacturer. It also strengthens our hypothesis that layers of technique have an impact on the decision of non-abandonment. After calculating the standardised coefficient, it is observed that the average (more efficient) technology has a stronger positive effect than the worst technique. One can give the same argument as is given in sub-section 2.1.

As the age of the manufacturer increases, other things being equal, one can expect has decision about abandonment to change. Above the age of more than 45, this variable has no role. So the effect is insignificant. Whereas the other two segments have a positive significant effect. By using standardised coefficient it is observed that the second segment has more effect than the first one.

\section{CONCLUSION AND POLICY IMPLICATIONS}

The development of non-traditional methods for studying the behaviour of economic variables has opened up a vast range of applications. This study made use of this development in attempting to analyse the behaviour of firms within the agricultural manufacturing machinery in Multan division. The main objective of this research, therefore, has been to estimate and analyse the exit behavior of manufacturer of the above mentioned firms, and its implication with reference to the hysteresis and layers of techniques theories. Specially, the analysis is centered on the estimation of parameters related to sunk capital cost, sunk labour cost and the value of waiting. Based on the two approaches developed by Professor P.N. Mathur and Professor Dixit, the one way classification and the logit model was adopted as the main theoretical tool or framework to perform the necessary estimation.

The following main conclusions emerge from this study.

(i) Hypothesis tests indicate that the psychological state of the manufacturer is different before the time of entry and exit from the market.

(ii) The evidence indicates that the behaviour of manufacturers is partially dependent on the expectations about the brightness of future and partially which technology they use in the production process.

(iii) The demographic characteristics of the manufacturers, and their segments inter alia, are the main instrument in their decision-making.

(iv) It was also observed that a pair of targets (as explained by Dixit) have a significant effect and determined the value of waiting. 
(v) Temporary shut down is not possible in the firms under study because of not only the chances of rusting problem of the machinery but also the cost of losing the trained labour force which will be absorbed by them.

(vi) Two approaches, hysteresis and layers of technique, are found not to substitute but complement each other.

(vii) The results of the logit model are also consistent with the simple analysis of one way classification but it gives a future insight in the level of significance of each segment.

The conclusions of the study can be used to derive some important policy implications.

As long as the behaviour of the manufacturer concerned is not guided by any agency or authority, there is a need to change the attitude and awareness of the local investors. Government should establish infrastructure in its broadest sense-the educational, technological, financial, and physical, environmental, and social. Another role of the government is in supporting the financial sector. Sometime depicted as the "brain" of the economy, the financial sector is responsible for deploying scarce capital resources in the most efficient way. It is concerned with gathering, processing, and disseminating information about precisely those areas in which market failures are often most marked. It is the duty of government to look after those firms which are observing and absorbing the losses especially those firms which are using obsolete technologies that are on the verge of obsolescence.

This study points to a number questions that warrant further investigation. Additional research is needed to extend and improve the database for firms earning normal profits and sick firms. This would require the information about the year when the firms converted into sick units. The data at disaggregated level are also required, i.e., about each and every single unit of the firms. The information about the retrofitting is also needed, i.e., when and where these have taken place and what is their intensity.

Another very worthwhile area for future research could involve adjustments in the model itself. A mathematical model should be developed which incorporates both of the variables i.e., layers of techniques and economic hysteresis. Some adjustments can be made in relation to the following.

(i) State of technology; best, average, worst.

(ii) Retrofitting.

(iii) Rate of loss comparable to prevailing price.

(iv) Target rate of loss at the time of absorbing loss.

(v) Target rate of return at the time of entry.

The analysis also requires information about those manufacturers who left the market. 


\section{REFERENCES}

Awa, and Batra (1988) Technological Capability and Firm Efficiency in Taiwan. The World Economic Review 12:1.

Azid T., and D. Ghosh (1998) Economics of Professor, P. N. Mathur. Economic and Political Weekly 33:39 2512-2517

Dixit, Avinash (1989) Hysteresis, Import Penetration, and Exchange Rate Pass Through. Quarterly Journal of Economics 104: 205-228.

Dixit, Avinash (1989a) Entry and Exit Decisions under Uncertainty. Journal of Political Economy 97: 620-638.

Dixit, Avinash (1991) Irreversible Investment with Price Ceiling. Journal of Political Economy 99: 541-557.

Dixit, Avinash (1992) Investment and Hysteresis. Journal of Economic Perspectives 6: 107-132.

Hartman, Richard (1972) The Effects of Price of and Cost Uncertainly on Investment. Journal of Economic Theory 5:2 258-66.

Henry, Claude (1974) Investment Decisions under Uncertainty: The Irreversibility Effect. American Economic Review 64:6 1006-12.

Law, and Azid (1993) The Causes of Non-abandonment: Layers of Techniques or Hysterics. Pakistan Economic and Social Review 31:1 25-37.

LAM, Pak-Sang (1989) Irreversibility and Consumer Durables Expenditures. Journal. of Monetary Economics 23: 135-50.

Mathur, P. N. (1967) An Approach System for Deflation of Sectoral Income in a Developing Economy Illustrated by the Industrial Sector of the Indian Economy from 1951 to 1965. Review of Income and Wealth Series 13:1 1-11.

Mathur, P. N. (1972) The Rate of Interest in a State of Flux. In Essay in Modern Economies. M. Parkin and A. R. Norbay (eds) The Proceedings of the Association of University Teachers of Economies, Aberystwyth, UK.

Mathur, P. N. (1977) A Study of Sectoral Prices and Their Movements in the British Economy in an Input-Output Framework. In W. W.Leontief (eds) Structure, System and Economic Policy. Cambridge University Press.

Mathur, P. N. (1986) Technical Progress, Price Change in Monopolistic and Competitive Industries, Phillips Curve and Its Shift With High Interest RateU.S.A. (Discussion Paper No. 08) London: Economics Deptt. Univ. College of London

Mathur, P. N., and P. Livas (1988) Policy and Planning of Embodied Technical Change. Paper Presented at the International Meeting on the Problems of Compilation of Input-Output Tables, Baden, Austria.

Mathur, P. N. (1989) Cost Variability Within U.S. Manufacturing Industry, Return to Scale, Product Mix and Suitable Industry Classification for Studying Technical Change. Paper presented at the 9th International Conference on Input-Output Techniques, Keszthely, Hungary. 
Mathur, P. N. (1989) Embodied Technical Change and Technological Transfer. Paper presented at the 9th International Conference on Input-output Techniques, Keszthely, Hungry.

Mathur, P. N. (1990) Why Developing Countries Fail to Develop. London: Macmillan.

Mc Donald, Robert, and Doniel Siegel (1985) Investment and the Valuation of Firms when there is an Option to Shut Down. International Economic Review 26: 33149.

Mc Donald, Robert, and Doniel Siegel (1986) The Value of Waiting to Invest. Quarterly Journal of Economics 101: 707-727.

Nickell, Stephen (1974) On the Role of Expectations in the Pure Theory of Investment. Review of Economic Studies 41: 1-19.

Pindyck, Robert S. (1988) Irreversible Investment, Capacity Choice, and the Value of the Firm. American. Economic Review 78:5 969-85.

Pindyck, Robert S. (1991) Irreversibility, Uncertainty, and Investment. Journal of Economic Literature 24: 1110-48.

Pindyck, Robert S. (1992) Adjustment Costs, Uncertainty and Behaviour of the Firm. American Economic Review 72: 415-426.

Schmalensee, R. (1972) Option Demand and Consumer's Surplus: Valuing Price Change under Uncertainty. American Economic Review 62:5 813-24.

Summers, Lawrence H. (1987) Investment Incentives and the Discounting of Depreciation/Allowances. In Martin Feldstein (ed.) The Effect of Taxation on Capital Accumulation. Chicago: University of Chicago Press.

Rashid, Z. A. (1989) Technological Obsolescence, Market and Prices Structure on the 1968, 1974 and 1979. British Vintage Technologies-An Input-Output Approach. Ph.D Thesis Submitted to the University of Wales, Unpublished.

Rashid, Z. A. (1989a) Price Structure, Technological Obsolescences and Labour Productivity—A Vintage Approach. Singapur Economic Review 34: 50-67. 